\title{
KALA-AZAR IN CHILDREN OF NORTH CHINA
}

\author{
BY
}

\author{
ANNIE V. SCOTT, M.D., and P. K. LI, M.B. \\ (From the Cheeloo University Hospital, Tsinan, Shantung, China.)
}

Our experience with kala-azar among children is limited to that of two provinges of North China, Hopei and Shantung, and covers the years 1921 to 1930 inclusive. The cases admitted to our service entered through our regular clinic in the city, as we have not attempted to handle these cases in the outlying endemic village districts. We recently had in the clinic at one time a case of chronic malarial fever, a left-sided psoas abscess and a case of kala-azar, each coming from a kala-azar region, and the parent, in each case, announced that he had brought the child for treatment of kala-azar.

L. E. Napier' has published several detailed accounts of the clinical and laboratory findings of kala-azar as seen in India. His notes often record cases occurring in children, but we are unable to find any investigation of kala-azar, either in India or China, which is confined to the disease as it occurs in children. In discussing the signs and symptoms of kala-azar in India, Napier states that they ' are most characteristic from 4 to 14 years.' If this is true, it seems well to review the records of a number of children suffering from this disease, and to attempt to formulate a clinical picture of the child affected with it. With this purpose in view, we have reviewed the histories of one hundred children treated on our service. Fifty of these cases were treated between 1924 and 1927, and fifty between 1928 and 1930. In both groups consecutive cases were taken, in order to avoid the possibility of selecting any outstanding symptoms.

By recording a few typical case histories and the physical and laboratory findings in a number of cases of kala-azar occurring in children of North China, we hope to furnish information which may be of assistance to physicians caring for children suffering from this disease.

\section{Case reports.}

Case 1.-R. W., an American child, female, 2 years of age, became ill February 3rd, 1922. The chief complaints were fever and general malaise. Daily examinations showed no remarkable physical signs. As there was a family history of pulmonary tuberculosis, a careful search was made for the disease. Pirquet's test was negative. X-ray examination of the chest showed no changes of importance. During the second week of illness the patient had a daily afternoon elevation of temperature not exceeding $102^{\circ}$. From February 10th to 28 th the temperature was irregular, ranging from $101^{\circ}$ in the morning to $105^{\circ}$ in the afternoon. During this period the patient's appetite was good. She slept well, played normally, and lost very little weight. 
On March 16th the spleen was found enlarged $3 \mathrm{~cm}$. below the left costal margin in the nipple line. The liver extended one finger-breadth below the right costal margin in the nipple line. Blood examination, March 16th, showed red blood cells 4,875,000; Hb. 70 per cent.; white cells 7,150; (polymorphonuclears 35 per cent., lymphocytes 35 per cent., large mononuclears 30 per cent.). On March 18th, Leishmania donovani bodies were found in films made from material aspirated from the spleen.

Some physicians record as a finding characteristic of kala-azar a double rise of temperature within twenty-four hours. Among 120 cases where fourhourly records were kept, only one child showed this double rise.

Case 2. - Li Yu Shan, male, 4.1 years of age, was admitted to hospital with the complaint of fever for one month. This fever was reported as being highest in the afternoon (see Chart). During this febrile period, a mass had appeared below the left costal margin and was gradually increasing in size.

Physical examination showed a slightly anæmic, normally developed child. Nutrition was good. There were no remarkable findings on physical examination, except that the spleen was enlarged $7 \mathrm{~cm}$. below the costal margin in the left nipple line. The liver was not enlarged. Films made from material aspirated from the spleen showed Leishmania donovani bodies.

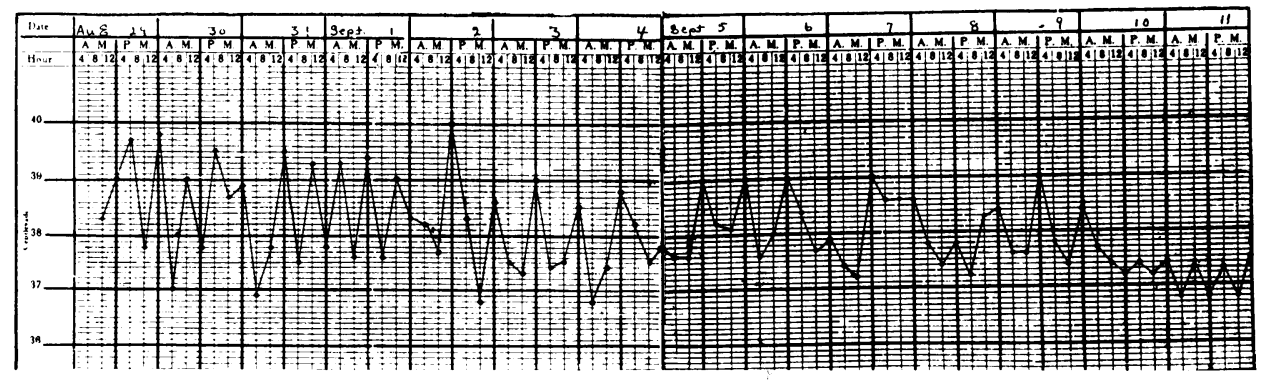

Case 3.-Kiang Nai Hsun, male, aged 7 years and 10 months, entered hospital November 17th, 1930. The chief symptoms which brought the patient to the hospital were enlargement of the abdomen, masses in the upper abdomen, loss of appetite, daily fever and frequent epistaxis. The illness began in May, 1927, with fever and loss of appetite. The parents reported that, after one month of fever, the patient became very emaciated and a mass was palpated below the left costal margin. This mass gradually increased in size and epistaxis occurred frequently. After the fever had continued for two months, a mass was first palpated beneath the right costal margin. The parents reported that the patient had suffered from continuous tever from the onset of the illness.

This is a typical history of kala-azar children coming to us from the villages of Shantung.

\section{Analysis of 100 cases in children.}

Sex.-According to information secured from parents coming from kala-azar regions, there is no reason to believe that male children contract the disease more frequently than females. The larger number of males in our figures in children (Table 1) is the same as that seen in our total kala-azar cases. These figures merely mean that some Chinese parents feel it is more necessary to try to preserve the lives of their sons than of their daughters, 
Age.-A large number of our cases come from country districts, necessitating several days' travel in order to reach us. These villagers frequently tell us that, in their home village, there are infants only a few months of age apparently suffering from the same disease, but prevented from coming for treatment because of the difficulties of travel. The youngest infant we have seen in the clinic suffering from kala-azar was eight months of age.

TABLE 1.

Sex and age incinences in 100 cases.

\begin{tabular}{|c|c|c|c|c|}
\hline & & \multicolumn{3}{|c|}{ Age. } \\
\hline nex. & No. Cilses. & Eldest. & Joungest. & Average. \\
\hline Male & 79 & 12 years & 1 year 6 months & 7 years 1 month \\
\hline Female & 21 & 11 years & 3 years 4 months & 7 years 10 months \\
\hline
\end{tabular}

History. - The incidence of the disease in the patient's family and among neighbours, the type of onset and the history of symptoms are as reliable as such data can be when collected from parents, relatives or neighbours of the patient.

It is certainly true that persons coming from an endemic region are alert to notice the early symptoms of the disease. It is difficult to secure definite information regarding the course of temperature. Many cases give a history of irregular temperature which is also intermittent. Several come saying that, at the onset of the disease, they had a period of malarial fever. One thing true of all cases is that they run the irregular fever for a few weeks to a few months, before the spleen is enlarged below the costal margin. We have been surprised at the lack of history of loss of strength. Many of these little patients come from farm duties requiring physical endurance. It is remarkable to see these anæmic, emaciated children enter the clinic, having walked fifty or sixty miles in two or three days. The state of nutrition must be the chief factor in causing the gingivitis which affords an excellent nidus for Vincent's spirochætal infection, which is one of the most serious complications met in kala-azar children.

TABLE 2.

Clinical histories in 100 cases.

\begin{tabular}{|c|c|c|c|c|c|c|c|c|c|}
\hline \multicolumn{3}{|c|}{$\begin{array}{c}\text { Duration of disease } \\
\text { in months. }\end{array}$} & \multicolumn{2}{|c|}{$\begin{array}{l}\text { History of disease } \\
\text { same as patient. }\end{array}$} & \multicolumn{5}{|c|}{ Symptons. } \\
\hline Max. & $\mathrm{Min}$. & Average. & Family. & Village. & $\begin{array}{l}\text { Temp. } \\
\text { irregr }\end{array}$ & $\begin{array}{l}\text { Diarr- } \\
\text { hera. }\end{array}$ & $\begin{array}{l}\text { Epis- } \\
\text { taxis. }\end{array}$ & $\begin{array}{l}\text { Bleeding } \\
\text { from } \\
\text { gums. }\end{array}$ & $\begin{array}{l}\text { Loss of } \\
\text { strength }\end{array}$ \\
\hline 42 & 1 & $\begin{array}{l}11 \text { months } \\
24 \text { days }\end{array}$ & 17 & 54 & 93 & 20 & $3 \pi$ & 27 & 23 \\
\hline
\end{tabular}


Physical findings at time of admission.-There are given in the list below the measurements of the spleen and liver taken in the nipple line from the costal margin to the lower border of the organ.

\begin{tabular}{|c|c|c|c|c|c|}
\hline Enlargement of spleen & $\ldots$ & $\ldots$ & $\left\{\begin{array}{l}\max . \\
\text { min. } \\
\text { average }\end{array}\right.$ & $\begin{array}{c}25 \\
3 \\
10 \cdot 9\end{array}$ & $\begin{array}{l}\mathrm{cm} . \\
9, \\
9,\end{array}$ \\
\hline Enlargement of liver ... & $\cdots$ & $\cdots$ & $\left\{\begin{array}{l}\max . \\
\min . \\
\text { average }\end{array}\right.$ & $\begin{array}{r}10 \\
2 \\
4\end{array}$ & $\begin{array}{l}\text { cm. } \\
, \\
,\end{array}$ \\
\hline Cancrum oris & ... & $\cdots$ & $\cdots$ & 6 & cases. \\
\hline Edema (feet) & $\ldots$ & $\ldots$ & $\ldots$ & 7 & , \\
\hline Heart, functional murm & & $\ldots$ & ... & 55 & , \\
\hline Lungs, findings importal & & $\ldots$ & ... & 0 & , \\
\hline Otitis media & $\cdots$ & $\cdots$ & $\cdots$ & 4 & , \\
\hline Congested superficial abd & lomin & veins & $\cdots$ & 8 & , \\
\hline Pigmentation of skin inc & reased & $\ldots$ & $\cdots$ & 17 & , \\
\hline
\end{tabular}

In practically all cases of cancrum oris, the process starts at the gum margin and occurs most frequently in cases with spirochætal infection of the gums. Noma of the cheek, when found, occurs in cases with low red blood counts and suffering from marked malnutrition. CEdema of the feet and legs also occurs with very poor nutrition. It is interesting to see the localized systolic heart murmur disappear as the child's blood-picture and general nutrition improve As most of our patients come from villages where the young boys wear lirtle clothing, it is very difficult to judge as to pigmentation of the skin. The pigmentation which we have recorded is dark brown, distributed over the lateral sides of face, external surfaces of forearms, dorsum of the hands, dorsum of the feet and extensor surfaces of the legs.

Enlargement of the spleen is a constant sign in patients coming to us with kala-azar. Case No. 1, which was under our care from the onset of illness, showed a spleen $3 \mathrm{~cm}$. below the left costal margin six weeks after the onset of the symptoms. Most parents say that the mass was first palpated below the left costal margin, one to three months after the child began to run irregular fever. There is a constant relation between the period of illness and the size of the spleen. Many cases show no enlargement of the liver, even when the spleen extends well into the left lower quadrant of the abdomen. Malnutrition is not listed in the above findings, for every child coming to us with kala-azar shows malnutrition. More often than loss of strength loss of weight is given as one of the progressing clinical symptoms of kala-azar in children. The child who has been ill with kala-azar for six months is emaciated, looks tired and anæmic, and has a markedly enlarged abdomen. The child who has had kala-azar one year is the typical faminedistrict child :- - peaked features, tired, disinterested eyes, limbs covered with skin only, swollen feet, protuberant abdomen. His one desire in life is to be fed and allowed to sleep almost continuously. 
Laboratory examinations at time of admission.-Stool cultures and smears from the gums were made in certain cases only; the other laboratory results reported were routine work.

Routine examination of stool-smears gave the following results:ascaris ova, 54 cases; hookworm ova, 10 cases; trichomonas, whipworm, and giardia, 1 case each. On stool culture, dysentery bacilli were found in 3 cases. In the examinations of smears from the gums the spirochæte and fusiform bacilli of Vincent's infection were found in 41 cases.

Later investigations lead us to believe that our figures are low for incidence of intestinal bacillary dysentery infection and for Vincent's spirochætal infection of the gums.

The children showing abnormal urinary findings have normal kidney function, and the abnormal findings in the urine rapidly disappeared as the child's general condition improved under kala-azar treatment. The routine urinary analyses showed negative results in 83 cases; and albumin and casts in 16 and 6 cases respectively.

TABLE 3.

BLOOD AND PUNCTURE FXAMINATIONS.

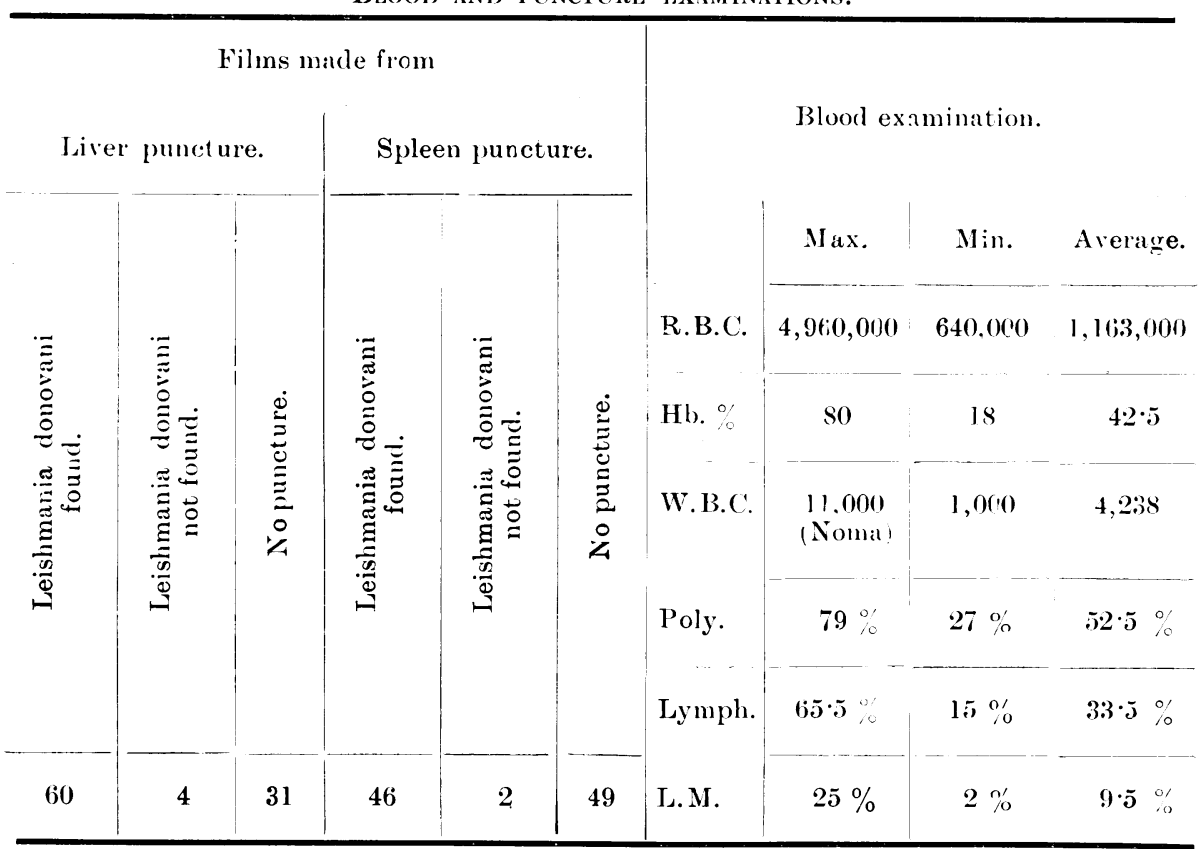

The characteristic blood-picture of our kala-azar cases shows a low total white count and an increase of large mononuclear cells. The hæmatocytic change is that found in marked secondary anæmia.

We have found that films made from material aspirated from the spleen afford the most rapid and accurate diagnosis of kala-azar. Even in cases with prolonged bleeding time we feel it is safe to do a spleen puncture. If it 
is possible (where the bleeding time is prolonged) we transfuse before the initial spleen puncture.

Practically all our patients suffering from kala-azar show a positive serum globulin test" ${ }^{2}$ which persists, following treatment, even after the spleen films are negative for Leishmania donovani bodies. We feel warranted in doing a spleen puncture to search for Leishmania donovani bodies, if a patient shows positive serum-globulin test. This test consists in adding a small quantity of blood, obtained by skin puncture, to 10 to 30 times its volume of distilled water contained in a small test tube. In kala-azar the solution becomes turbid at once, and, on standing, a heavy, white precipitate is formed. (Our routine is blood $29 \mathrm{c.mm}$. , distilled water $0.6 \mathrm{c.cm}$. )

\section{Summary.}

By means of case reports and tabulations of clinical and laboratory findings, we have attempted to give a picture of the child of North China suffering from kala-azar. He is distinctly a child suffering from a chronic devitalizing malady. He comes from a village where the disease is endemic, or has recently resided in such a district. He has suffered from irregular fever and progressive loss of weight since the onset of the illness. The child is emaciated, looks anæmic and always has enlargement of the abdomen. Secondary anæmia, with a low total white count and increase of the large monocytes are the characteristic laboratory findings. The enlargement of the spleen is definitely related to the period of illness. Heart and kidney signs when present are not serious and clear up under treatment for kala-azar.

\section{REFERENGES.}

1. Napier, L. E., Ind. Med. Gaz., Calcutta, 1921, LVI, 401.

2. Hsieh, H. P., and Hsien Wu, China Med. J., 1921, XXXV, 527.

Enitors' Note.-It is hoped to publish later a further paper by the authors dealing with the treatment of Kala-azar. 